\title{
Dynamics of Area Substitution of Edible Oilseeds in India
}

\author{
Rahul Banerjee* and Bishal Gurung \\ ICAR-Indian Agricultural Statistics Research Institute, New Delhi-110012, India \\ *Corresponding author
}

\begin{tabular}{l} 
K e y w o r d s \\
Oilseeds; Area \\
substitution; \\
Retention \\
Probability; Land \\
use pattern \\
\hline Article Info \\
Accepted: \\
15 May 2020 \\
Available Online: \\
10 June 2020
\end{tabular}

\section{A B S T R A C T}

Oilseeds are an indispensable crop in India since it contributes substantially to agriculture in terms of farm income, employment and export earnings. It has been observed that there are fluctuations in the area under various oilseed crops in India. It was seen that two oilseed crops namely castor and sunflower had a high retention capability and rapeseed and mustard had a relatively stable retention capability in all the analyzed states. The low retention probability for few oilseeds may be due to tough competition presented and greater market diffusion efforts made by other oilseeds. Further, it was concluded that India should not have high reliance on one oilseed so as to evade trade risks in the long run. Therefore, suitable policies need to be envisioned to diversify the geographical concentration of oilseed production and minimize market risks.

\section{Introduction}

Oilseed crops occupy a conspicuous place in the agricultural economy of India. Apart from cereal crops, Oilseeds are among the foremost crops that are grown in the country. India is the highest producer of Oilseeds in the world and it contributes about 7 per cent of the global vegetable oils production. It also occupies 14 per cent share of the world area wise and 9-10 per cent of the total edible oils consumption (Jha et al., 2012).The major Oilseeds producing states are Madhya
Pradesh, Gujarat, Rajasthan, Andhra Pradesh and Karnataka. Among different Oilseeds, groundnut, rapeseed-mustard and soybean account for about 80 per cent of area and 87 per cent of production of oilseeds in the country (2010-11).

The Oilseed sector has a great potential for extra added growth. A good source of growth in Oilseed crops is the technological component ingrained in the lower cost and no cost tools established for proficient field management of the crop. 
Constant burden on agricultural area, insecurity in food and alteration required to climate change have made combined assessment and modelling of future agroecosystems development more and more imperative. Numerous statistical tools are employed to support the decision making and planning in agriculture. An essential constituent in this is the concept of crop modelling and forecasting. One such very powerful approach to crop modelling is the probability model based on Markov Chain theory. A heartening feature is that the interval estimates obtained by Markov Chain models are not inhibited by a parametric conjecture and are robust against outliers and extreme values.

Mahendra Singh (2012) studied the structural changes in land utilization pattern and shifting of area among different land use classes in India using Markov chain analysis. Subash et al., (2011) studied the rainfall availability at weekly intervals during the crop season and the probability of occurrence of two and three consecutive dry and wet weeks through Markov chain modeling approach. Various other workers have also made use of Markov chain for analysis in agricultural research in India (Eldo et al., 2014, Singh 2012, Kar et al., 2006, Das et al., 2006, Kar 2002 and Gupta et al., 1996).

Accordingly, in this paper, we make use of some concepts of Markov Chain to analyze the dynamics of area substitution of Oilseeds in different states of Indiaby estimating the probability of retention and substitution.

\section{Materials and Methods}

A Markov chain is a mathematical system that undergoes transition from. A Markov chain is a mathematical system that undergoes transitions from one state to another on a state space. It is a random process where the next state depends only on the current state and not on the sequence of events that preceded it. The changes in the area of Oilseeds were analysed by employing a first order finite Markov chain model which evaluated thenet effect in changes in the area of Oilseeds over a period of time. First order Markov Chain model was used to determine Transition Probability Matrix (TPM) to explain how areas between Oilseeds have shifted over the years. The off-diagonal elements of TPM represent switching-over probability and diagonal element indicate the retention probability.The element $\mathrm{P}_{i j}$ of the matrix indicated the probability that the area would switch from the $i^{\text {th }}$ oilseed crop to the $j^{\text {th }}$ oilseed crop over a period of time. In the context of the current application, we have estimated the TPM to explain how cropped areas for Oilseeds like groundnut, castor, sesame, rapeseed and mustard, soybean, and sunflower in different states of India and India as a whole have changed. The general form of first order MCM is given as:

$X_{j t}=X_{j t-1} P_{i j}+\varepsilon_{j t}$

where, $X_{j t}=$ Area under the ' $j^{\text {th }}$, oilseed crop during the year ' $t$ '.

$\mathrm{X}_{\mathrm{jt}-1}=$ Area under the ${ }^{\mathrm{j}} \mathrm{j}$ ' ' oilseed crop during the year $\mathrm{t}-1$.

$P_{i j}=$ Probability that area shifts from the $i^{\text {th }}$ oilseed to the $\mathrm{j}^{\text {th }}$ oilseed and

$\mathrm{n}=$ number of crops included in the model.

The transitional probabilities $\mathrm{P}_{\mathrm{ij}}$ have the properties:

$0 \leq \mathrm{P}_{\mathrm{ij}} \leq 1$

The $\mathrm{P}_{\mathrm{ij}}$ matrix was estimated in the linear programming framework using method of minimization of mean absolute deviation, as Min I $\mathbf{\varepsilon}$ 
Subject to $\mathbf{X P}{ }^{*}+\varepsilon=\mathbf{Y}, \mathbf{M P}^{*}=\mathbf{1}, \mathbf{P}^{*}=\mathbf{0}$

Where, $\mathrm{P}^{*}$ is a vector probabilities $\mathrm{P}_{\mathrm{ij}}$,

$\mathrm{I}$ is an identity matrix of appropriate dimension,

$\varepsilon$ is the vector of absolute errors

$\mathrm{Y}$ is the vector of area of each crop,

$\mathrm{X}$ is a block diagonal matrix of lagged values of $\mathrm{Y}$, and

$M$ is a grouping matrix to add the row elements of $\mathrm{P}$ arranged in $\mathrm{P}^{*}$ to unity.

\section{Results and Discussion}

The changing patterns of area under oilseeds were estimated by obtaining the transitional probability matrices for the period 2002 to
2012. The major Oilseeds growing states, Andhra Pradesh, Madhya Pradesh, Karnataka, and Rajasthan were considered for analysis. The data were obtained from the published sources of Directorate of Economics and Statistics; Commission for Agricultural Costs and Prices, Ministry of Agriculture, GoI. The results of transitional probability matrix are presented in Tables1-5. Rows of the matrix show the area of the corresponding crop group lost to the other crop groups whereas columns indicate area gained by the respective crop group. It is evident from Table 1, that the area under sesame in Andhra Pradesh has been replaced to a considerable extend by Castor, indicated by the value of 0.67 .

Table.1 Transitional probability matrix of area under oilseed crops in Andhra Pradesh

\begin{tabular}{|c|c|c|c|c|c|c|}
\hline & GROUND NUT & CASTOR & SESAME & RAPESEED AND MUSTARD & SOYABEAN & SUNFLOWER \\
\hline $\begin{array}{c}\text { GROUND } \\
\text { NUT }\end{array}$ & 0.105 & 0.224 & 0.224 & 0.001 & 0.224 & 0.223 \\
\hline CASTOR & 0.001 & 0.231 & 0.675 & 0.001 & 0.092 & 0.001 \\
\hline SESAME & 0.001 & 0.022 & 0.363 & 0.002 & 0.130 & 0.481 \\
\hline RAPESEED & 0.001 & 0.001 & 0.036 & 0.830 & 0.134 & 0.001 \\
\hline SOYABEAN & 0.017 & 0.001 & 0.001 & 0.627 & 0.356 & 0.001 \\
\hline SUNFLOWER & 0.001 & 0.181 & 0.001 & 0.001 & 0.001 & 0.817 \\
\hline
\end{tabular}

Table.2 Transitional probability matrix of area under oilseed crops in Karnataka

\begin{tabular}{|c|c|c|c|c|c|c|}
\hline & GROUND NUT & CASTOR & SESAME & RAPESEED AND MUSTARD & SOYABEAN & SUNFLOWER \\
\hline $\begin{array}{c}\text { GROUND } \\
\text { NUT }\end{array}$ & 0.159 & 0.001 & 0.151 & 0.349 & 0.221 & 0.119 \\
\hline CASTOR & 0.001 & 0.123 & 0.039 & 0.823 & 0.009 & 0.004 \\
\hline SESAME & 0.004 & 0.001 & 0.047 & 0.778 & 0.140 & 0.031 \\
\hline RAPESEED & 0.001 & 0.001 & 0.001 & 0.999 & 0.001 & 0.001 \\
\hline SOYABEAN & 0.048 & 0.473 & 0.001 & 0.001 & 0.478 & 0.001 \\
\hline SUNFLOWER & 0.005 & 0.001 & 0.153 & 0.460 & 0.001 & 0.382 \\
\hline
\end{tabular}


Table.3 Transitional probability matrix of area under oilseed crops in Madhya Pradesh

\begin{tabular}{|c|c|c|c|c|c|c|}
\hline & $\begin{array}{c}\text { GROUND } \\
\text { NUT }\end{array}$ & CASTOR & SESAME & $\begin{array}{c}\text { RAPESEED } \\
\text { AND } \\
\text { MUSTARD }\end{array}$ & SOYABEAN & SUNFLOWER \\
\hline GROUND NUT & 0.298 & 0.349 & 0.003 & 0.001 & 0.002 & 0.347 \\
\hline CASTOR & 0.152 & 0.042 & 0.006 & 0.006 & 0.001 & 0.794 \\
\hline SESAME & 0.001 & 0.001 & 0.762 & 0.227 & 0.005 & 0.005 \\
\hline RAPESEED & 0.405 & 0.008 & 0.001 & 0.176 & 0.016 & 0.395 \\
\hline SOYABEAN & 0.150 & 0.259 & 0.259 & 0.035 & 0.242 & 0.054 \\
\hline SUNFLOWER & 0.001 & 0.001 & 0.001 & 0.001 & 0.001 & 0.999 \\
\hline
\end{tabular}

Table.4 Transitional probability matrix of area under oilseed crops in Rajasthan

\begin{tabular}{|c|c|c|c|c|c|c|}
\hline & $\begin{array}{c}\text { GROUND } \\
\text { NUT }\end{array}$ & CASTOR & SESAME & $\begin{array}{c}\text { RAPESEED } \\
\text { AND } \\
\text { MUSTARD }\end{array}$ & SOYABEAN & SUNFLOWER \\
\hline $\begin{array}{c}\text { GROUND } \\
\text { NUT }\end{array}$ & 0.223 & 0.125 & 0.011 & 0.001 & 0.112 & 0.530 \\
\hline CASTOR & 0.099 & 0.497 & 0.022 & 0.001 & 0.008 & 0.374 \\
\hline SESAME & 0.001 & 0.001 & 0.073 & 0.001 & 0.348 & 0.579 \\
\hline RAPESEED & 0.268 & 0.001 & 0.091 & 0.144 & 0.271 & 0.224 \\
\hline SOYABEAN & 0.274 & 0.014 & 0.001 & 0.027 & 0.246 & 0.438 \\
\hline SUNFLOWER & 0.005 & 0.001 & 0.001 & 0.001 & 0.001 & 0.993 \\
\hline
\end{tabular}

Table.5 Transitional probability matrix of area under oilseed crops in India

\begin{tabular}{|c|c|c|c|c|c|c|}
\hline & $\begin{array}{c}\text { GROUND } \\
\text { NUT }\end{array}$ & CASTOR & SESAME & $\begin{array}{c}\text { RAPESEED } \\
\text { AND } \\
\text { MUSTARD }\end{array}$ & SOYABEAN & SUNFLOWER \\
\hline GROUND NUT & 0.229 & 0.143 & 0.197 & 0.001 & 0.006 & 0.424 \\
\hline CASTOR & 0.001 & 0.984 & 0.001 & 0.001 & 0.016 & 0.001 \\
\hline SESAME & 0.085 & 0.310 & 0.297 & 0.001 & 0.075 & 0.232 \\
\hline RAPESEED & 0.197 & 0.002 & 0.261 & 0.401 & 0.003 & 0.136 \\
\hline SOYABEAN & 0.005 & 0.280 & 0.410 & 0.001 & 0.304 & 0.001 \\
\hline SUNFLOWER & 0.001 & 0.001 & 0.001 & 0.001 & 0.001 & 0.999 \\
\hline
\end{tabular}

Rapeseed has a high retention probability, 0.83 which indicates that areas under rapeseed are hard toreplace by other oilseed crop. From Table 2, we can interpret that in Karnataka, sesame has a very low retention probability, while rapeseed and mustard has a retention probability of unity approximately, which suggests that farmers do not go for other crops in areas where rapeseed and mustards are grown in Karnataka at all while areas where sesame are grown are readily replaced by other crops. A perusal of Table 3 suggests that in Madhya Pradesh, sesame and sunflower has a high retention probability. In Rajasthan, area under Castor and Sunflower are retained by the farmers while areas under 
sesame are readily replaced by other oilseed crops. An overall picture of area substitution of oilseeds in India is presented in Table 5. It suggests that area under Castor and Sunflower are hard to replace. Further, Rapeseed and Mustard has a good retention probability suggesting that in India as a whole the area under rapeseed and mustard are not easy to be replaced by other oilseeds.

The observed substitution between oilseeds might be promising because of the similarities in the production requirement including climatic condition and inputs as the entire crop groups are mostly grown in marginal land rather than productive area and under rain fed conditions. The TPM also admit that the preferences for rapeseed and mustard was distinct over other crops as no significant area of rapeseed and mustard was shifted to other crop groups over the years. This may be due to the fact that the seed replacement rate for all oilseed crops apart from rapeseed and mustard has failed to show a substantial growth.

In this paper markov chain analysis of area substitution among Oilseeds in different states of India has indicates that rapeseed and mustard has a relatively good retention capability. The low retention probability for few Oilseeds in some states may be attributed to the stiff competition offered and higher market penetration efforts made by other Oilseeds in the respective states.

A very low retention probability reflects the inability to retain the share in the traditional growing area and explore new areas. The transitional probability matrix shows that India should not have high dependency on one Oilseed alone, so as to avoid trade risks in the long-run. Therefore, appropriate strategies have to be envisaged to diversify the geographical concentration of Oilseed production and minimize market risks.

\section{References}

Das, P. K., Subash, N., Sikka, A. K., Sharda, V. N. and Sharma, N. K. (2006). Modelling weekly rainfall using gamma probability distribution and Markov chain for crop planning in a sub-humid (dry) climate of central Bihar. Indian Journal of Agricultural Sciences, 76, 358-61.

Eldo, M. K., Rajesh, M. K., Jamshinath, T. P., Hemalatha, N., Murali, G. and George, V. T. (2014). Development of a tool for computational prediction of 70 promoters in Pseudomonas spp using SVM and HMM approaches. Indian Journal of Agricultural Sciences,84, 119-23.

Gupta, V. K., Agrawal, K. K., Upadhyay, A. K. andShanker, U. (1997). Reliability of medium-range weather forecast for Jabalpur region of Madhya Pradesh. Indian Journal of Agricultural Sciences, 67, 120- 23.

Jha, G.K., Pal, S., Mathur, V.C.,Bisaria, G., Anbukkani, P., Burman, P.R., Dubey, S.K. (2012). Edible Oilseeds Supply and Demand Scenario in India: Implications for Policy. Project Report. Published by: Director, IARI, New Delhi

Kar, G. (2002). Rainfall variability and probability analysis for studying waterharvesting potential and crop diversification. Indian Journal of Agricultural Sciences, 72, 364-66.

Kar, G., Verma, H. N. and Singh, R. (2006). Enhancing rainwater-use efficiency and stabilizing productivity of rainfed up land through rice (Oryza sativa)-based intercropping. Indian Journal of Agricultural Sciences, 76, 33-36

Singh, M. (2010). Projection of land use pattern in India: A markov chain approach.Annals of Agricultural Research, 33, 69-78. 
Singh, M. (2010). Projection of potato export from India: Amarkov chain approach. Potato J., 37, 48-55.

Subash, N., Ram Mohan, H.S. and Sikka, A. $\mathrm{K}$. (2011).Integrating rainfall probability and moisture availability index for crop planning during kharif rice (Oryza sativa) in eastern IndoGangetic basin. Indian Journal of Agricultural Sciences, 81, 843-51.

\section{How to cite this article:}

Rahul Banerjee and Bishal Gurung. 2020. Dynamics of Area Substitution of Edible Oilseeds in India. Int.J.Curr.Microbiol.App.Sci. 9(06): 598-603.

doi: https://doi.org/10.20546/ijcmas.2020.906.077 